\title{
Short communication: Development of an equation for estimating methane emissions of dairy cows from milk Fourier transform mid-infrared spectra by using reference data obtained exclusively from respiration chambers
}

\author{
A. Vanlierde, ${ }^{*}$ H. Soyeurt, † N. Gengler,† F. G. Colinet, † E. Froidmont,† M. Kreuzer,§ F. Grandl,\# M. Bell,II \\ P. Lund,ף D. W. Olijhoek, П M. Eugène, ${ }^{* *}$ C. Martin, ${ }^{* *} B$. Kuhla, $\dagger^{1}{ }^{1}$ and $F$. Dehareng* \\ *Walloon Agricultural Research Centre, Valorization of Agricultural Products, 5030 Gembloux, Belgium \\ †Gembloux Agro-Bio Tech, University of Liège, Agrobiochem Department and Research and Teaching Centre (TERRA), 5030 Gembloux, Belgium \\ $\ddagger$ Walloon Agricultural Research Centre, Production and Sectors Department, 5030 Gembloux, Belgium \\ §ETH Zürich, Institute of Agricultural Sciences, 8092 Zürich, Switzerland \\ \#Qualitas AG, 6300 Zug, Switzerland \\ IIAgri-Food and Biosciences Institute, Large Park, Hillsborough, BT26 6DR, United Kingdom \\ IDepartment of Animal Science, AU Foulum, Aarhus University, 8830 Tjele, Denmark \\ **UMR Herbivores, INRA, VetAgro Sup, Université Clermont Auvergne, 63122 Saint-Genès-Champanelle, France \\ ††Leibniz Institute for Farm Animal Biology (FBN), Institute of Nutritional Physiology, 18196 Dummerstorf, Germany
}

\begin{abstract}
Evaluation and mitigation of enteric methane $\left(\mathrm{CH}_{4}\right)$ emissions from ruminant livestock, in particular from dairy cows, have acquired global importance for sustainable, climate-smart cattle production. Based on $\mathrm{CH}_{4}$ reference measurements obtained with the $\mathrm{SF}_{6}$ tracer technique to determine ruminal $\mathrm{CH}_{4}$ production, a current equation permits evaluation of individual daily $\mathrm{CH}_{4}$ emissions of dairy cows based on milk Fourier transform mid-infrared (FT-MIR) spectra. However, the respiration chamber $(\mathrm{RC})$ technique is considered to be more accurate than $\mathrm{SF}_{6}$ to measure $\mathrm{CH}_{4}$ production from cattle. This study aimed to develop an equation that allows estimating $\mathrm{CH}_{4}$ emissions of lactating cows recorded in an RC from corresponding milk FT-MIR spectra and to challenge its robustness and relevance through validation processes and its application on a milk spectral database. This would permit confirming the conclusions drawn with the existing equation based on $\mathrm{SF}_{6}$ reference measurements regarding the potential to estimate daily $\mathrm{CH}_{4}$ emissions of dairy cows from milk FT-MIR spectra. A total of $584 \mathrm{RC}$ reference $\mathrm{CH}_{4}$ measurements (mean \pm standard deviation of $400 \pm 72 \mathrm{~g}$ of $\mathrm{CH}_{4} / \mathrm{d}$ ) and corresponding standardized milk mid-infrared spectra were obtained from 148 individual lactating cows between 7 and $321 \mathrm{~d}$ in milk in 5 European countries (Germany, Switzerland, Denmark, France, and Northern Ireland). The developed equation based on RC measurements showed calibration and cross-validation coefficients of determination of 0.65 and 0.57 , respectively, which is lower than
\end{abstract}

Received January 19, 2018

Accepted April 1, 2018.

${ }^{1}$ Corresponding author: b.kuhla@fbn-dummerstorf.de those obtained earlier by the equation based on 532 $\mathrm{SF}_{6}$ measurements (0.74 and 0.70 , respectively). This means that the RC-based model is unable to explain the variability observed in the corresponding reference data as well as the $\mathrm{SF}_{6}$-based model. The standard errors of calibration and cross-validation were lower for the RC model ( 43 and $47 \mathrm{~g} / \mathrm{d}$ vs. 66 and $70 \mathrm{~g} / \mathrm{d}$ for the $\mathrm{SF}_{6}$ version, respectively), indicating that the model based on RC data was closer to actual values. The root mean squared error (RMSE) of calibration of $42 \mathrm{~g} / \mathrm{d}$ represents only $10 \%$ of the overall daily $\mathrm{CH}_{4}$ production, which is $23 \mathrm{~g} / \mathrm{d}$ lower than the RMSE for the $\mathrm{SF}_{6^{-}}$ based equation. During the external validation step an RMSE of $62 \mathrm{~g} / \mathrm{d}$ was observed. When the RC equation was applied to a standardized spectral database of milk recordings collected in the Walloon region of Belgium between January 2012 and December 2017 (1,515,137 spectra from 132,658 lactating cows in 1,176 different herds), an average \pm standard deviation of $446 \pm 51 \mathrm{~g}$ of $\mathrm{CH}_{4} / \mathrm{d}$ was estimated, which is consistent with the range of the values measured using both $\mathrm{RC}$ and $\mathrm{SF}_{6}$ techniques. This study confirmed that milk FT-MIR spectra could be used as a potential proxy to estimate daily $\mathrm{CH}_{4}$ emissions from dairy cows provided that the variability to predict is covered by the model.

Key words: cattle, greenhouse gas, spectroscopy, proxy

\section{Short Communication}

Increasing sustainability and profitability while reducing the environmental footprint of dairy production is, among others, a major challenge for the breeding sector. The reduction of greenhouse gas emissions is one of the key factors in meeting these intentions. A reliable method for obtaining $\mathrm{CH}_{4}$ measurements on 
large numbers of individual cows in commercial farms is needed. Reliable measurement of $\mathrm{CH}_{4}$ emissions from these dairy cows is time consuming and expensive; thus, the development of proxies to estimate individual emissions is warranted (Negussie et al., 2017).

Predicting daily $\mathrm{CH}_{4}$ emissions of dairy cows from milk Fourier transform mid-infrared (FT-MIR) spectra is a promising approach (Dehareng et al., 2012; Vanlierde et al., 2015; Vanlierde et al., 2016). In industrial countries, milk FT-MIR spectra are already collected routinely at a reasonable cost in the context of milk recording programs. However, the existing prediction equation for daily $\mathrm{CH}_{4}$ emissions from milk FT-MIR spectra is based on reference $\mathrm{CH}_{4}$ measurements obtained using the $\mathrm{SF}_{6}$ tracer technique (Vanlierde et al., 2016), which only quantifies enteric $\mathrm{CH}_{4}$. On the another hand, recent investigations have developed similar models using the "sniffer" method to measure $\mathrm{CH}_{4}$ emissions on a large number of dairy cows. However, results obtained did not confirm the potential to estimate $\mathrm{CH}_{4}$ from milk FT-MIR spectra only (Shetty et al., 2017). Considering that the respiration chamber $(\mathbf{R C})$ technique is praised as the gold standard method capable of measuring total $\mathrm{CH}_{4}$ emitted by cattle (Hammond et al., 2016), the objective of the present study was to develop a new prediction equation based exclusively on reference data obtained from RC measurements. The robustness and relevance of this equation were tested through validation processes and the application on a milk spectral database. This work will also permit developing an equation based on the $\mathrm{RC}$ measurement technique, which gives predictions in an $\mathrm{RC}$ range as $\mathrm{RC}$ take into account emissions from the lower digestive tract (unlike the $\mathrm{SF}_{6}$ technique). The ability to predict $\mathrm{CH}_{4}$ emission from milk FT-MIR spectra will be discussed.

A total of 584 reference $\mathrm{CH}_{4}$ measurements (400 \pm $72 \mathrm{~g} / \mathrm{d}$ ) from 148 individual lactating cows were obtained in open-circuit RC from studies across Europe: Germany, Switzerland, Denmark, France, and Northern Ireland (the facilities used are described in Yan et al., 2000; Derno et al., 2009; Hellwing et al., 2012; Guyader et al., 2015; Grandl et al., 2016). Consequently, this data set represents different feeding regimens, climates, breeds, and feed types. Cows were housed in individual $\mathrm{RC}$ for a minimum of $3 \mathrm{~d}$, and $\mathrm{CH}_{4}$ production was measured for at least 2 consecutive 24 -h periods while cows were fed ad libitum. Individual milk samples were taken during a.m. and p.m. milkings from the same days. The corresponding milk samples were collected and analyzed after sampling to obtain FT-MIR spectra. The a.m. and p.m. spectra were linked to a daily spectrum by a weighted average based on the a.m. and p.m. milk yields. The averaged milk FT-MIR spectra were then related to the corresponding 24-h $\mathrm{CH}_{4}$ measure-
Table 1. Distribution of parity and stage of lactation of cows used to develop methane emission prediction equations based on respiration chamber reference measurements

\begin{tabular}{lrrrr}
\hline & \multicolumn{3}{c}{ Parity } & \\
\cline { 2 - 4 } DIM & 1 & 2 & $>2$ & Total \\
\hline $1-50$ & 1 & 28 & 13 & 42 \\
$51-100$ & 3 & 5 & 9 & 17 \\
$101-150$ & 3 & 8 & 13 & 24 \\
$151-200$ & 1 & 9 & 18 & 28 \\
$>200$ & 8 & 15 & 14 & 37 \\
Total & 16 & 65 & 67 & 148 \\
\hline
\end{tabular}

ments. The reference data sets consisted of 211 data from Germany [50 Holstein (HO) cows, $406 \pm 60 \mathrm{~g} / \mathrm{d}$ of $\mathrm{CH}_{4}$ ], 138 data from Switzerland [40 Brown Swiss (BS), $9 \mathrm{HO}, 8$ Red HO, and $1 \mathrm{HO} \times$ Simmental cows, $450 \pm 76 \mathrm{~g} / \mathrm{d}$ of $\mathrm{CH}_{4}$ ], 130 data from Denmark (9 HO and 10 Jersey cows, $366 \pm 64 \mathrm{~g} / \mathrm{d}$ of $\left.\mathrm{CH}_{4}\right), 81$ data from France (9 $\mathrm{HO}$ cows, $366 \pm 61 \mathrm{~g} / \mathrm{d}$ of $\mathrm{CH}_{4}$ ), and 24 data from Northern Ireland $(6 \mathrm{HO}$ and 6 Swedish Red Cross cows, $365 \pm 44 \mathrm{~g} / \mathrm{d}$ of $\left.\mathrm{CH}_{4}\right)$. These cows were of varying parities and DIM (Table 1).

To avoid any instrument interference and ensure that the milk FT-MIR spectra are comparable regardless of the spectrometer used and the date of analysis, the milk FT-MIR spectra were standardized according to the procedure described in Grelet et al. (2017). A first derivative was applied to the milk FT-MIR spectra as recommended by Soyeurt et al. (2011). The calibration process was developed from 3 spectral regions: between wavenumbers 968 and $1,577 \mathrm{~cm}^{-1}, 1,720$ and 1,809 $\mathrm{cm}^{-1}$, and 2,561 and $2,966 \mathrm{~cm}^{-1}(\mathrm{n}=289$ data points). Constant (P0), linear (P1), and quadratic (P2) modified Legendre polynomials were computed from DIM the day of $\mathrm{CH}_{4}$ measurement of the cows (Gengler et al., 1999) and applied to each wavenumber of spectra to take into account the metabolic status of cows during lactation (Vanlierde et al., 2015). The final modified spectra were based on $3 \times 289$ data points (867 data points). A modified partial least square (PLS) regression as implemented in the WINISI software (version 4.6; Foss, Hillerød, Denmark) was used.

The robustness of the calibration model was tested with a 5-group internal cross-validation procedure. Reference data were divided randomly into 5 groups, and 5 calibration models were developed by removing 1 individual group for each calibration development. Then, the removed group was predicted by the calibration model based on the 4 other groups. Moreover, as several measurements per cow are included in the database, a cow- and country-dependent external validation (CCDEV) was conducted using R (R Core Team, Vienna, Austria). To carry out this external validation, 
$20 \%$ of the cows were removed randomly and simultaneously per country (i.e., 10 cows from Germany, 12 from Switzerland, 4 from Denmark, 1 from France, and 2 from Northern Ireland). The calibration model was developed on the remaining $80 \%$ of cows, and subsequently the model was tested by predicting the removed data (Shetty et al., 2017). The country-dependent step ensured that the country's variability information (e.g., diet, management) would be considered in the model. Given that the database was not built for the purpose of developing this equation, the removal of some specific cows can have a deep effect on the statistics and, thus, on the conclusions. Therefore, the CCDEV process was repeated 500 times to test a maximum number of combinations, and the variations of the coefficient of determination $\left(\mathbf{R}^{2}\right)$ of CCDEV were observed.

The percentage of cows of each breed in the RC data set (percentage of data values) was $55 \%(68 \%) \mathrm{HO}$, $27 \%(14 \%)$ BS, $7 \%$ (11\%) Jersey, $5 \%$ (4\%) Red HO, $5 \%$ (2\%) Swedish Red Cross, and less than 1\% (less than $1 \%$ ) $\mathrm{HO} \times$ Simmental, meaning that there were 2 main breeds ( $\mathrm{HO}$ and $\mathrm{BS}$ ). A breed-specific model has been tested on these 2 most represented breeds to observe whether this permits more accuracy within each specific breed. The HO model was based on 398 reference values from 82 cows $\left(399 \pm 68 \mathrm{~g} / \mathrm{d}\right.$ of $\left.\mathrm{CH}_{4}\right)$, and the BS model was based on 80 reference values from 40 cows $\left(458 \pm 68 \mathrm{~g} / \mathrm{d}\right.$ of $\left.\mathrm{CH}_{4}\right)$. A PLS regression was performed as described before, with a 5-group crossvalidation process and a cow- and breed-dependent external validation (CBDEV). Regarding this CBDEV step, $20 \%$ of cows were removed randomly and simultaneously per breed, and the calibration models were developed for each breed on the remaining cows of this breed and subsequently tested using the removed data. Regarding the lower number of possible combinations in comparison with the entire $\mathrm{RC}$ data set, the CBDEV process was repeated 20 times per breed.

To evaluate the accuracy of the model for each data set, the root mean squared errors of calibration (RMSEC) for the total data set and for each country's data set independently and the root mean squared errors of prediction (RMSEP) for the CCDEV and CBDEV steps were computed as follows:

$$
\operatorname{RMSE}=\sqrt{\frac{\sum_{i-1}^{n}\left|\varepsilon_{i}\right|^{2}}{n}},
$$

where $n$ was the number of observations and $\varepsilon_{i}$ was the difference between the measured $\mathrm{CH}_{4}$ and corresponding estimated $\mathrm{CH}_{4}$ values for the $i$ th observation.

To assess the consistency of the predictions obtained with this new equation based on RC measurements, this equation was applied to the Walloon milk recording standardized spectral database, which contains spectral data collected between January 2012 and December 2017. In the present analysis, only records from HO cows collected between 5 and 365 DIM (the range of modified Legendre polynomials) in the first 3 lactations were considered, leading to a total of $1,679,728$ standardized spectral records. To ensure that the spectral variability of the milk recording samples was covered by the equation, only the spectra with a standardized Mahalanobis distance (global H distance) lower than 3 were used in this study (e.g., Shenk and Westerhaus, 1991; Soyeurt et al., 2012). During this process a moderate amount $(9.8 \%)$ of the spectra was

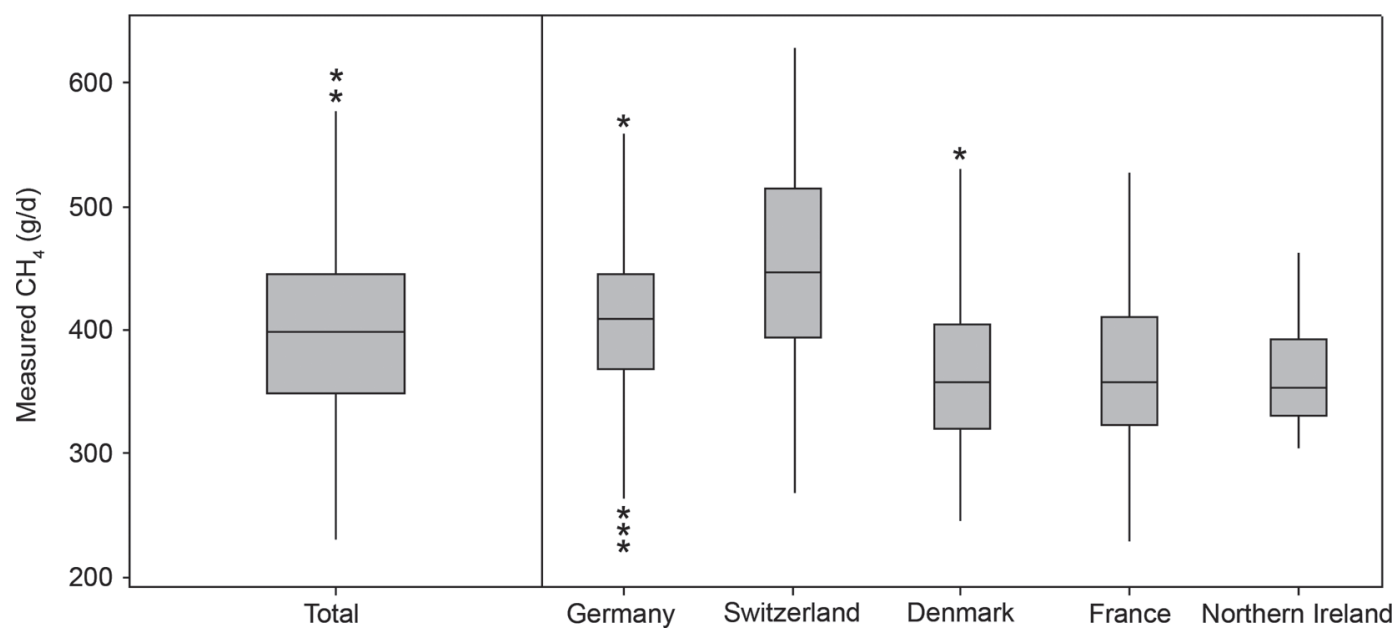

Figure 1. Boxplot of methane measurements obtained in respiration chambers for the entire data set and per country. Boxplot of methane measurements obtained in respiration chambers for the entire data set (Total) and per country. The boxes identify interquartile ranges (Q1-Q3), the solid black mid line indicates the median, whiskers end at the lowest and highest values that are not extreme values, and asterisks represent extreme values. 
Table 2. Distribution and general statistics regarding reference methane measurements in a respiration chamber $(\mathrm{g} / \mathrm{d})$ and methane predictions (g/d) from milk Fourier transform mid-infrared spectra in individual European countries

\begin{tabular}{|c|c|c|c|c|c|c|c|c|c|c|}
\hline Country & $\begin{array}{c}\text { No. of } \\
\text { data }\end{array}$ & \multicolumn{4}{|c|}{ Reference data } & \multicolumn{4}{|c|}{ Predicted data } & RMSEC \\
\hline Switzerland & 138 & 450 & 76 & 266 & 630 & 444 & 58 & 283 & 557 & 47 \\
\hline Denmark & 130 & 366 & 64 & 244 & 556 & 368 & 51 & 226 & 472 & 38 \\
\hline France & 81 & 366 & 61 & 229 & 527 & 366 & 38 & 293 & 439 & 47 \\
\hline Northern Ireland & 24 & 365 & 44 & 304 & 464 & 366 & 16 & 342 & 398 & 36 \\
\hline
\end{tabular}

${ }^{1}$ Root mean squared error of calibration.

removed. Finally, $\mathrm{CH}_{4}$ predictions lower than $150 \mathrm{~g} / \mathrm{d}$ and higher than $950 \mathrm{~g} / \mathrm{d}$ were considered outliers (Vanlierde et al., 2015) and excluded from this study (206 predicted data). In the end, $1,515,137 \mathrm{CH}_{4}$ predicted values were used to test the practical application of the equation. These represented 1,176 different herds and 132,658 individual cows.

The results obtained with the milk FT-MIR model designed to predict $\mathrm{CH}_{4}$ emissions $(\mathrm{g} / \mathrm{d}$ ) based on $\mathrm{RC}$ measurements were encouraging. The correlations between measured and predicted values during calibration and cross-validation were 0.8 and 0.75 , respectively, and confirmed the relevance of evaluating the $\mathrm{CH}_{4}$ emissions from milk FT-MIR spectra. Regarding the statistical performance of the RC-based model built on 14 terms (vs. 10 terms for the $\mathrm{SF}_{6}$-based equation), the calibration $\mathrm{R}^{2}$ was 0.65 for the $\mathrm{RC}$-based equation versus 0.74 for the $\mathrm{SF}_{6}$-based equation (Vanlierde et al., 2016). The cross-validation $\mathrm{R}^{2}$ was 0.57 for the $\mathrm{RC}$ based equation versus 0.70 for the $\mathrm{SF}_{6}$-based equation. The $\mathrm{R}^{2}$ are highly dependent on the range and variability of the data. In comparison with $\mathrm{SF}_{6}$ measurements, the lower observed $\mathrm{R}^{2}$ for $\mathrm{RC}$ is probably partly due to the lower range of reference values [from 229 to $630 \mathrm{~g} / \mathrm{d}$ of $\mathrm{CH}_{4}$ (vs. 180 to $802 \mathrm{~g} / \mathrm{d}$ for the $\mathrm{SF}_{6}$ data set) with a mean \pm standard deviation of $400 \pm 72 \mathrm{~g} / \mathrm{d}$ (vs. $430 \pm$ $129 \mathrm{~g} / \mathrm{d}$ for the $\mathrm{SF}_{6}$ data set)]. Moreover, the development of a calibration equation requires a sufficiently varied set of data (Davies and Fearn, 2006). However, this European data set was collated from independent studies in each country, usually for the purpose of comparing $\mathrm{CH}_{4}$ emissions in response to different dietary treatments. Therefore, animals that were closely comparable in terms of milk yield and lactation stages were used in each country. This explains why the data sets regarding the number of animals, data, diets, RC type, and so on are different among countries; ideally, they should be more comparable. Figure 1 illustrates the distribution of $\mathrm{CH}_{4}$ measurements for the entire data set and for each individual country. As expected regarding the previous remarks, the distribution of the reference data appeared to vary between countries and can induce a "country effect." Ideally, these issues could be dealt with by enlarging the number and therefore the variability of the reference data in each country. Nevertheless, in the present study, collaboration between research institutes allowed merging the available data sets and gave the opportunity to design a European data set with RC measurements from individual cows of different genetic background and fed differing diets. This translated into greater variability than that obtained within individual countries as well as in terms of range of reference $\mathrm{CH}_{4}$ measurements (required for the calibration process) regarding the zootechnical aspects (e.g., covered breeds, diets, DIM). In the present case, the variability in lactation stages, parity, milk yield, feed intake, and $\mathrm{CH}_{4}$ emission of this Europe-wide $\mathrm{RC}$ data set was not as well-balanced as that in the data set obtained from $\mathrm{SF}_{6}$ measurements. Indeed, the reference data set for the $\mathrm{SF}_{6}$-based equation was deliberately collected for the purpose of creating an equation able to predict $\mathrm{CH}_{4}$ values from milk FT-MIR spectra, meaning that a maximum number of scenarios (e.g., measurements on cows of different parities, with lactation stage not represented in the model, fed with specific diets) were intentionally researched. Nonetheless, even with nonoptimal variability, the observed linear relationship between measured and predicted $\mathrm{CH}_{4}$ emissions (Figure 2) implies that FT-MIR spectra predictions are correlated with $\mathrm{CH}_{4}$ production measured in RC. The standard error of calibration was $43 \mathrm{~g} / \mathrm{d}$ for RC (vs. 66 $\mathrm{g} / \mathrm{d}$ for $\mathrm{SF}_{6}$ ), and the standard error of cross-validation was $47 \mathrm{~g} / \mathrm{d}$ (vs. $70 \mathrm{~g} / \mathrm{d}$ for $\mathrm{SF}_{6}$ ). With a lower standard error of cross-validation, the $\mathrm{RC}$-based predictions are closer to the actual values than the $\mathrm{SF}_{6}$ equation. The predictions of calibration data ranged between 226 and $557 \mathrm{~g} / \mathrm{d}$ of $\mathrm{CH}_{4}$, with an average \pm standard deviation of $400 \pm 58 \mathrm{~g} / \mathrm{d}$. As shown in Table 2, the means of the predictions are similar to the means of the measured data for each country as well as for the overall data set with RC. Noticeably, the standard deviations are systematically lower for the predictions than for the 


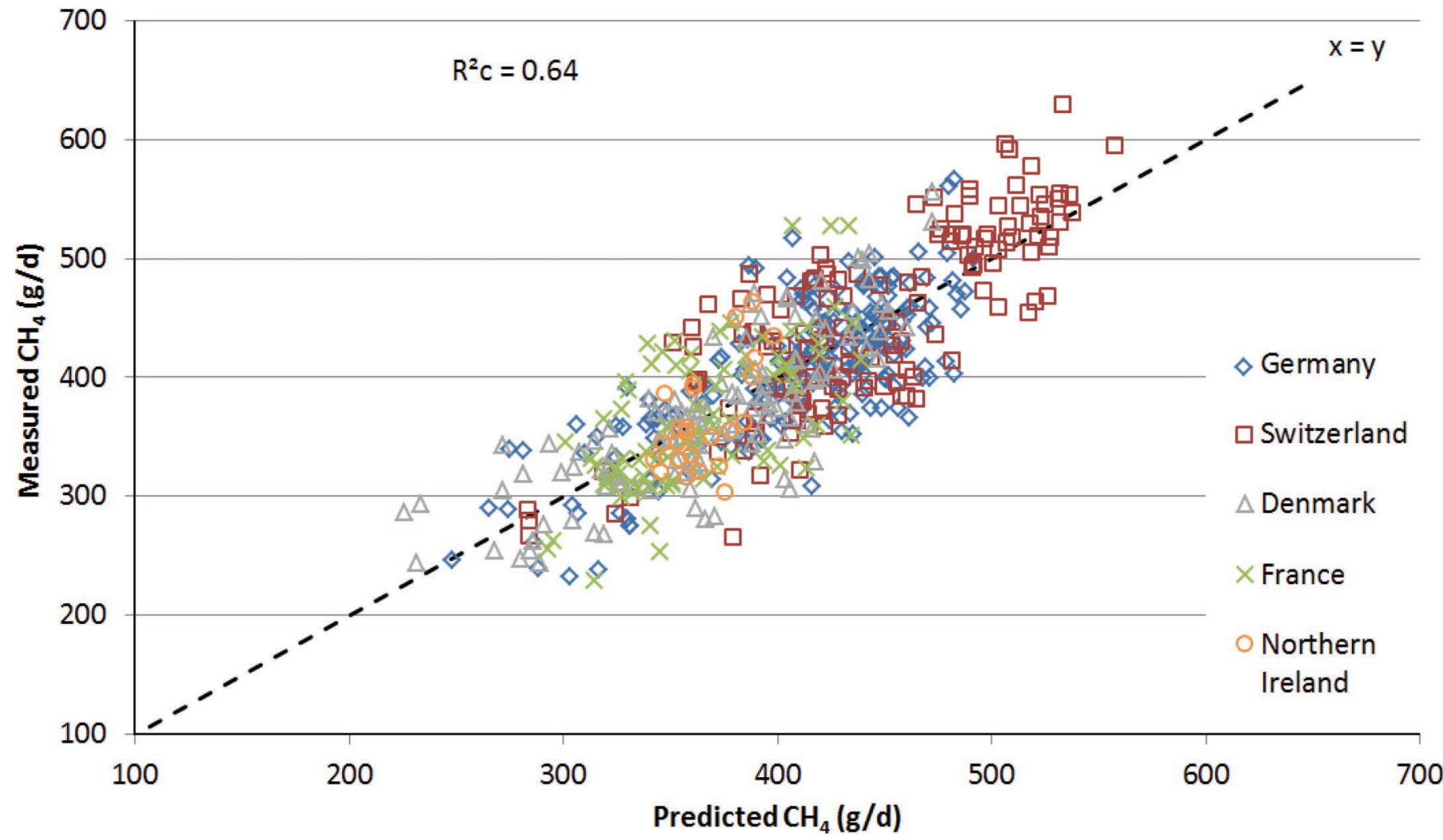

Figure 2. Relationship between predicted $\mathrm{CH}_{4}$ emissions (g/d) of dairy cows determined from milk mid-infrared spectra and $\mathrm{CH}_{4}$ emissions $(\mathrm{g} / \mathrm{d})$ of dairy cows measured in a respiration chamber. Data obtained from 584 daily $\mathrm{CH}_{4}$ measurements and corresponding milk Fourier transform mid-infrared spectra recorded in 5 European countries. Color version available online.

measurements. This could be a result of the modified PLS regression process, which tends to reduce the amplitude of prediction values compared with the amplitude of reference values. Indeed, this is intrinsic to the PLS regression. The lower the correlation, the more this phenomenon is accentuated.

The RMSEC of different countries ranged from 36 to $47 \mathrm{~g} / \mathrm{d}$ of $\mathrm{CH}_{4}$, and the overall RMSEC of $42 \mathrm{~g} / \mathrm{d}$ represented $10 \%$ of the overall mean $\mathrm{CH}_{4}$ value. This is lower than the RMSEC observed for the $\mathrm{SF}_{6}$-based model $\left(65 \mathrm{~g} / \mathrm{d}\right.$, which represents $15 \%$ of the $\mathrm{SF}_{6}$-based data set mean of $430 \mathrm{~g} / \mathrm{d}$ of $\left.\mathrm{CH}_{4}\right)$.

Interestingly, from Figures 1 and 2, only few data have measured or predicted values lower than $300 \mathrm{~g} / \mathrm{d}$ (low, $\mathrm{n}=40$ ) and almost only the Swiss data are $>500$ $\mathrm{g} / \mathrm{d}$ (high, $\mathrm{n}=54$ ). Because these low and high $\mathrm{CH}_{4}$ values are not often present and occur with less variability (animals, diets) than values between 350 and $450 \mathrm{~g} / \mathrm{d}$ (mid, $\mathrm{n}=295$ ), where most of the reference data are observed (Figure 1), it can be assumed that predictions for values lower than $300 \mathrm{~g} / \mathrm{d}$ of $\mathrm{CH}_{4}$ or greater than $500 \mathrm{~g} / \mathrm{d}$ of $\mathrm{CH}_{4}$ are less accurate. Indeed, the RMSEC were 51,36 , and $55 \mathrm{~g} / \mathrm{d}$ of $\mathrm{CH}_{4}$ for low, mid, and high values, respectively.
Concerning the CCDEV step, the averaged statistics after randomly removing $20 \%$ of the cows per country in a loop of 500 repetitions showed an $\mathrm{R}^{2}$ of $\mathrm{CCDEV}$ varying between 0.08 and 0.69 (with a mean of 0.40 ) and an RMSEP of CCDEV varying between 44 and 106 $\mathrm{g} / \mathrm{d}$ of $\mathrm{CH}_{4}$ (with a mean of $64 \mathrm{~g} / \mathrm{d}$ ) depending on the cows removed. These results demonstrate that the ability of the model to predict the validation data varies greatly depending on whether the cows included in the calibration data set include the necessary information for a valid prediction equation. This indicates that the model is not very robust in its current state, which is to be expected considering that the available data set was not collected for this purpose, but when the required variability is included in the model it is able to estimate the $\mathrm{CH}_{4}$ emission independently of the representation of a specific cow. The distribution of the RMSEP of CCDEV is detailed in Figure 3. It can be observed that in most cases RMSEP of CCDEV range between 55 and $75 \mathrm{~g} / \mathrm{d}$, meaning that they are higher than during the cross-validation process, which is expected because this validation is more stringent than the cross-validation.

Regarding the breed-specific test, the $\mathrm{HO}$ and BS models permitted us to obtain calibration $\mathrm{R}^{2}$ of 0.61 and 
0.78, RMSEC of 42 and $32 \mathrm{~g} / \mathrm{d}$ of $\mathrm{CH}_{4}$, cross-validation $\mathrm{R}^{2}$ of 0.48 and $0.46, \mathrm{R}^{2}$ of CBDEV of 0.33 (minimummaximum: $0.09-0.59$ ) and 0.31 (minimum-maximum: 0.01-0.74), and RMSEP of CBDEV of 70 (minimummaximum: 46-125) and 72 (minimum-maximum: 44-118) g/d of $\mathrm{CH}_{4}$, respectively. This shows that the calibration statistics are similar or even better for the breed-specific models than for the model including all available breeds, but during the cross-validation and the CBDEV steps statistics are worse. This means that these breed-specific models are less robust and that, at least at this stage, the other breeds add value to the global model.

When the equation developed with all the $\mathrm{RC}$ data was applied to the Walloon milk recording spectral database, the average predicted $\mathrm{CH}_{4}$ emissions were 444 $\pm 51 \mathrm{~g} / \mathrm{d}$ for first-lactation $(\mathrm{n}=659,457$ milk samples from 105,349 dairy cows in 1,166 herds), $449 \pm 51 \mathrm{~g} / \mathrm{d}$ for second-lactation $(\mathrm{n}=506,606$ milk samples from 81,863 dairy cows in 1,159 herds), and $448 \pm 50 \mathrm{~g} / \mathrm{d}$ for third-lactation cows $(\mathrm{n}=349,074$ milk samples from 57,112 dairy cows in 1,145 herds). The standard deviation in $\mathrm{CH}_{4}$ emissions was similar between parities. Even with the absence of Belgian data in the reference RC-based model, these predictions on the Belgian spectrum are consistent with regard to the expected range for lactating dairy cows and are included in the range of measured values of this study and the $\mathrm{SF}_{6}$ version of the equation (Vanlierde et al., 2016). The RC-based model confirms that the equation gives logical results in practice provided that the conditions of application are considered.

Regarding the $\mathrm{R}^{2}$ and the errors observed, the current potential of the RC-based equation permits at least distinguishing trends between animals (high or low daily $\mathrm{CH}_{4}$ emissions) provided that the variability (e.g., breed, diet) of the predicted sample is covered by the reference data available. The best assumptions for the lower statistics observed by Shetty et al. (2017) could be attributed to the sniffer reference technique to measure $\mathrm{CH}_{4}$, the different structures of the tested population, the duration of measurements (not a 24-h measurement, in contrast to $\mathrm{SF}_{6}$ or $\mathrm{RC}$ methods), and the time between $\mathrm{CH}_{4}$ measurement and milk sampling, which differs significantly between both studies.

As identified in the literature (Davies and Fearn, 2006) and previously observed in the development process of the equation based on $\mathrm{SF}_{6}$ measurements, the addition of new $\mathrm{RC}$ values with variability not yet included in the model (e.g., additional $\mathrm{CH}_{4}$ measurements linked to corresponding milk FT-MIR spectra from more cows with different diets) is expected to increase the accuracy and robustness of this equation.
For the purpose of enlarging the variability covered by the equation, further research could combine $\mathrm{RC}$ and $\mathrm{SF}_{6}$ data sets toward the development of a prediction model.

To conclude, an equation based on $\mathrm{CH}_{4}$ measurements obtained in RC and the corresponding milk FTMIR spectra has been developed. Even without an ideal composition of the reference data set collated from multiple research institutes, using different facilities, and during diet trials in which similar animals are often selected (factors that are not ideal), the final conclusions are comparable with previous findings with the $\mathrm{SF}_{6}$ reference technique to measure $\mathrm{CH}_{4}$ (Vanlierde et al., 2016). The lower $R^{2}$ values obtained with the $R C$ rather than the $\mathrm{SF}_{6}$ version of the equation can be attributed to the lower variability of the $\mathrm{RC}$ data set. This last point highlights the importance of collaborating in the development of more efficient calibration models by combining existing data sets and efforts to obtain a final data set as varied as possible. The study confirmed that milk FT-MIR spectra data are a relevant proxy to estimate individual daily $\mathrm{CH}_{4}$ emissions on commercial farms from individual milk samples. Existing equations still need to be improved through the inclusion of additional reference data covering more of the naturally occurring variability in the present reference data set. However, this approach provides a method for carrying out large-scale studies on individual lactating cows to estimate daily $\mathrm{CH}_{4}$ emissions and identifying mitigation options. Additionally, it would allow enteric $\mathrm{CH}_{4}$ to be included in genetic selection strategies of dairy cattle along with other current phenotypes of interest (e.g., milk yield, health, fertility).

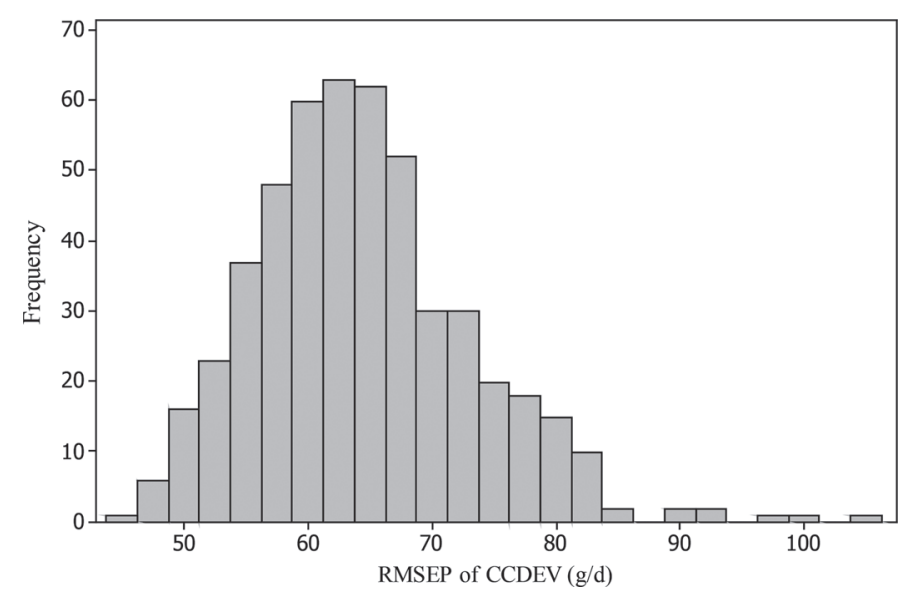

Figure 3. Distribution of the root mean squared error of prediction (RMSEP) during 500 repetitions of the cow- and country-dependent external validation (CCDEV). 


\section{ACKNOWLEDGMENTS}

The authors are grateful to their fellow researchers with regard to collecting methane and milk samples. The OptiMIR (INTERREG IVB North-West Europe funded; www.optimir.eu) and the COST Methagene (COST-Horizon 2020 funded; www.methagene.eu) European projects are gratefully acknowledged for facilitating networking between research teams and data exchange. The authors thank the Walloon Breeding Association (Ciney, Belgium) and Comité du lait (Battice, Belgium) for providing access to data related to the Walloon milk recording. The Association of Swiss Cattle Breeders (Zollikofen, Switzerland) is acknowledged for providing the milk Fourier transform mid-infrared spectral data of the Swiss samples. Part of the work has been funded by the EU project GplusE (http://www.gpluse.eu), especially research conducted at the Agri-Food and Biosciences Institute (AFBI) in Northern Ireland, and facilitation of data exchanges. The GplusE project has received funding from the European Union's Seventh Framework Programme for research, technological development, and demonstration under grant agreement $\mathrm{n}^{\circ} 613689$. The views expressed in this publication are the sole responsibility of the authors and do not necessarily reflect the views of the European Commission. Research conducted at Leibniz Institute for Farm Animal Biology (FBN) in Germany was partially funded by the optiKuh project supported by the German Federal Ministry of Food and Agriculture (BMBL) through the Federal Office for Agriculture and Food (BLE). Research conducted in France at the French National Institute for Agricultural Research (INRA) was funded by the French National Research Agency (ANR) through the Joint Programming Initiative on Agriculture, Food Security and Climate Change (FACCE-JPI). Global Network program (ANR-13-JFAC-0003-01). Research conducted in Denmark at Aarhus University was funded by the Danish Milk Levy Fund and Aarhus University.

\section{REFERENCES}

Davies, A. M. C., and T. Fearn. 2006. Back to basics: Calibration statistics. Spectroscopy Europe 18:31-32.

Dehareng, F., C. Delfosse, E. Froidmont, H. Soyeurt, C. Martin, N. Gengler, A. Vanlierde, and P. Dardenne. 2012. Potential use of milk mid-infrared spectra to predict individual methane emission of dairy cows. Animal 6:1694-1701. https://doi.org/10.1017/ S1751731112000456.

Derno, M., H. G. Elsner, E. A. Paetow, H. Scholze, and M. Schweigel. 2009. Technical note: A new facility for continuous respiration measurements in lactating cows. J. Dairy Sci. 92:2804-2808. https://doi.org/10.3168/jds.2008-1839.

Gengler, N., A. Tijani, G. R. Wiggans, and I. Misztal. 1999. Estimation of (co)variance function coefficients for test day yield with a expectation-maximization restricted maximum likelihood algo- rithm. J. Dairy Sci. 82:1849.e1-1849.e23. https://doi.org/10.3168/ jds.S0022-0302(99)75417-2.

Grandl, F., S. L. Amelchanka, M. Furger, M. Clauss, J. O. Zeitz, M. Kreuzer, and A. Schwarm. 2016. Biological implications of longevity in dairy cows: 2. Changes in methane emissions and efficiency with age. J. Dairy Sci. 99:3472-3485. https://doi.org/10.3168/jds .2015-10262.

Grelet, C., J. A. Fernandez Pierna, P. Dardenne, H. Soyeurt, A. Vanlierde, F. Colinet, C. Bastin, N. Gengler, V. Baeten, and F. Dehareng. 2017. Standardization of milk mid-infrared spectrometers for the transfer and use of multiple models. J. Dairy Sci. 100:79107921. https://doi.org/10.3168/jds.2017-12720.

Guyader, J., M. Eugène, B. Meunier, M. Doreau, D. P. Morgavi, M. Silberberg, Y. Rochette, C. Gérard, C. Loncke, and C. Martin. 2015. Additive methane-mitigating effect between linseed oil and nitrate fed to cattle. J. Anim. Sci. 93:3564-3577. https://doi.org/ $10.2527 /$ jas.2014-8196.

Hammond, K. J., L. A. Crompton, A. Bannink, J. Dijkstra, D. R Yáñez-Ruiz, P. O'Kiely, E. Kebreab, M. A. Eugène, Z. Yu, K. J. Shingfield, A. Schwarm, A. N. Hristov, and C. K. Reynolds. 2016. Review of current in vivo measurement techniques for quantifying enteric methane emission from ruminants. Anim. Feed Sci. Technol. 219:13-30. https://doi.org/10.1016/j.anifeedsci.2016.05.018.

Hellwing, A. L. F., P. Lund, M. R. Weisbjerg, M. Brask, and T. Hvelplund. 2012. Technical note: Test of a low-cost and animal-friendly system for measuring methane emissions from dairy cows. J. Dairy Sci. 95:6077-6085. https://doi.org/10.3168/jds.2012-5505.

Negussie, E., Y. de Haas, F. Dehareng, R. J. Dewhurst, J. Dijkstra, N. Gengler, D. P. Morgavi, H. Soyeurt, S. van Gastelen, T. Yan, and F. Biscarini. 2017. Invited review: Large-scale indirect measurements for enteric methane emissions in dairy cattle: A review of proxies and their potential for use in management and breeding decisions. J. Dairy Sci. 100:2433-2453. https://doi.org/10.3168/ jds.2016-12030.

Shenk, J. S., and M. O. Westerhaus. 1991. Population definition, sample selection, and calibration procedures for near infrared reflectance spectroscopy. Crop Sci. 31:469-474. https://doi.org/10 $.2135 /$ cropsci1991.0011183X003100020049x.

Shetty, N., G. Difford, J. Lassen, P. Løvendahl, and A. J. Buitenhuis. 2017. Predicting methane emissions of lactating Danish Holstein cows using Fourier transform mid-infrared spectroscopy of milk. J. Dairy Sci. 100:9052-9060. https://doi.org/10.3168/jds.2017-13014.

Soyeurt, H., C. Bastin, F. G. Colinet, V. M.-R. Arnould, D. P. Berry E. Wall, F. Dehareng, H. N. Nguyen, P. Dardenne, J. Schefers, J. Vandenplas, K. Weigel, M. Coffey, L. Théron, J. Detilleux, E. Reding, N. Gengler, and S. McParland. 2012. Midinfrared prediction of lactoferrin content in bovine milk: Potential indicator of mastitis. Animal 6:1830-1838. https://doi.org/10.1017/ S1751731112000791.

Soyeurt, H., F. Dehareng, N. Gengler, S. McParland, E. Wall, D. P. Berry, M. Coffey, and P. Dardenne. 2011. Mid-infrared prediction of bovine milk fatty acids across multiple breeds, production systems, and countries. J. Dairy Sci. 94:1657-1667. https://doi.org/ 10.3168 /jds.2010-3408

Vanlierde, A., M.-L. Vanrobays, F. Dehareng, E. Froidmont, H. Soyeurt, S. McParland, E. Lewis, M. H. Deighton, F. Grandl, M. Kreuzer, B. Gredler, P. Dardenne, and N. Gengler. 2015. Hot topic: Innovative lactation-stage-dependent prediction of methane emissions from milk mid-infrared spectra. J. Dairy Sci. 98:57405747. https://doi.org/10.3168/jds.2014-8436.

Vanlierde, A., M.-L. Vanrobays, N. Gengler, P. Dardenne, E. Froidmont, H. Soyeurt, S. McParland, E. Lewis, M. H. Deighton, M. Mathot, and F. Dehareng. 2016. Milk mid-infrared spectra enable prediction of lactation-stage-dependent methane emissions of dairy cattle within routine population-scale milk recording schemes. Anim. Prod. Sci. 56:258-264. https://doi.org/10.1071/AN15590.

Yan, T., R. E. Agnew, F. J. Gordon, and M. G. Porter. 2000. The prediction of methane energy output in dairy and beef cattle offered grass silage-based diets. Livest. Prod. Sci. 64:253-263. https://doi .org/10.1016/S0301-6226(99)00145-1. 